\title{
OS LIVROS DIDÁTICOS DE QUÍMICA INDICADOS PELO PNLD 2015: A HISTÓRIA DA CIÊNCIA EMPREGADA NA TEMÁTICA “QUANTIDADE DE MATÉRIA” E SUA UNIDADE, MOL
}

\author{
S. O. FRANCO-PATROCÍNIO* e I. FREITAS-REIS \\ Universidade Federal de Juiz de Fora \\ sandra.franco.ufjf@outlook.com
}

Submetido 08/06/2016 - Aceito 08/02/2017

DOI: $10.15628 /$ holos. 2017.4676

\section{RESUMO}

É comum na literatura da área de ensino de química a discussão da importância que o livro didático apresenta nas salas de aula. Nesse sentido, o presente artigo analisa os livros didáticos de química brasileiros indicados pelo Plano Nacional do Livro Didático (PNLD). Procuramos investigar como a história da ciência é empegada nessas obras, especificamente na temática quantidade de matéria. Discutimos a importância de incluir a história da ciência nos livros didáticos de forma que o educando compreenda a natureza do conhecimento científico. Para tal pesquisa, nos alicerçamos nas categorias criadas por Laurinda Leite
(2002) e adaptadas por Vidal (2009) e também nos resultados encontrados anteriormente por Rogado (2000). Podemos perceber que é constante a busca dos órgãos competentes governamentais pela melhoria da qualidade dos livros didáticos distribuídos nas escolas públicas brasileiras, entretanto, mesmo nenhuma das obras tendo deixado de tratar do assunto, os livros didáticos apresentam um debate historiográfico sobre a temática bastante tímido, sendo a história da ciência apresentada a partir de uma abordagem histórica parcial, considerada na maioria das vezes em recortes do texto principal e figuras dos pesquisadores.

PALAVRAS-CHAVE: livro didático, história da ciência, quantidade de matéria, ensino médio, ensino de química

\section{THE CHEMISTRY TEXTBOOKS INDICATED BY PNLD 2015: THE SCIENCE HISTORY USED IN THE SUBJECT “MATTER QUANTITY” AND ITS UNIT, MOL}

\begin{abstract}
It is common in the literature of the chemistry teaching area the discussion about the importance that the textbook has in the classrooms. In this regard, this paper analyzes the Brazilian chemistry textbooks indicated by Textbook National Plan (Plano Nacional do Livro Didático - PNLD). We seek to investigate how the science history is used in these works, mainly in the subject matter quantity. We discuss the importance to include the science history in the textbooks so that the student can understand the nature of the scientific knowledge. For such research, our grounds are the categories created
\end{abstract}

by Laurinda Leite (2002) and adapted by Vidal (2009) and in the results previously found by Rogado (2000). We can note that is constant the search of the government appropriate agencies by improvement of the quality of the textbooks distributed in the Brazilian public schools. However, even though none of the works having failed to address the matter, the textbooks have a historiographical debate about the subject very shy, with the science history being shown from a partial history approach, considered mostly in clippings of the main text and images of the researchers.

KEYWORDS: textbook, science history, matter quantity, high school, chemistry teaching 


\section{INTRODUÇÃO}

Ao fazermos uma revisão das pesquisas publicadas, percebemos que os conceitos relacionados a quantidade de matéria, constante de Avogadro e a unidade mol, são inseridos no ensino básico de maneira direta objetivando, geralmente, que o aluno seja capaz de realizar cálculos nos quais o valor da constante e a unidade de medida mol são solicitados para a solução de problemas, estequiométricos ou equivalentes. Assim o educando não compreende como se deu a construção de tais conhecimentos. Característica esta, que se prolonga no ensino superior, já que os alunos chegam à universidade com defasagem na aprendizagem de diversos conceitos.

Nesse sentido, encontramos na literatura diversos trabalhos dedicados aos problemas envolvidos no processo de ensino-aprendizagem do conceito de quantidade de matéria e do mol.

No âmbito internacional, Dierks (1981) afirmou que após 1953 até a produção de seu trabalho - cerca de três décadas depois - já haviam sido publicados aproximadamente 300 artigos discutindo o conceito de mol, e apesar disso, o problema ainda persistia.

Furió, Azcona e Guisasola, publicaram em 2002, um artigo intitulado "Revisión de investigaciones sobre la enseñanza-aprendizaje de los conceptos cantidad de sustância y mol", em que consideraram mais de uma centena de publicações - nas principais revistas internacionais que se tratavam da temática quantidade de matéria e mol, a maioria dos trabalhos publicados referiam-se as dificuldades que os docentes enfrentavam ao lecionar tal conteúdo; as dificuldades no aprendizado do conceito quantidade de matéria e da unidade, mol; o conhecimento prévio que o educando devia possuir para compreender tal conhecimento e também a análise do assunto nos livros didáticos. Em relação aos docentes, foi percebido uma discrepância entre o que é aceito pela comunidade científica e o pensamento dos professores. Esse desacordo influencia no ensino nos seguintes aspectos:

a) O conceito de quantidade de matéria não é introduzido na grande maioria dos programas educacionais de química. Nesse sentido, é geralmente identificado a quantidade de matéria como massa ou como número de entidades elementares, ignorando o seu significado atual, como uma quantidade para contar as partículas. b) Os termos quantidade de matéria e mol são confundidos com conceitos contidos na teoria atômico-molecular, tais como massa molar, constante de Avogadro... c) Dificuldades de sequenciamento dos conteúdos para introduzir o conceito de mol e a inadequação das metodologias de ensino comumente usados (p. 238).

Já em relação ao estudantes, os autores concluíram:

a) Os alunos carecem de uma concepção científica do mol. b) A grande maioria dos estudantes identificou o mol como uma massa, como um volume ou como um número de entidades elementares. c) Os estudantes desconhecem o significado da grandeza "Quantidade de substância", evitando sua utilização e não identificam o mol como sua unidade. d) Os alunos confundem frequentemente o nível macroscópico de representação (massa molar) com o microscópico (massa atômica e massa molecular). e) Os alunos frequentemente identificam a proporção de moléculas com a proporção de massas e a proporção de massas com a proporção de massas molares (p. 238).

Trabalho realizado posteriormente à publicação de Furió, Azcona e Guisasola, foi o desenvolvido por Abrantes, Vieira e Silva em 2003. As pesquisadoras trabalharam com docentes 
com vários anos de experiência, com graduandos de licenciatura, além de alunos cursistas do primeiro ano de química na Universidade de Aveiro. A partir de um questionário, foi possível constatar que muitos docentes apresentavam uma definição inadequada sobre a temática, além de não ter sido observado entre os professores conhecimentos relacionados a origem e evolução do conceito de mol. Em relação aos alunos, as autoras perceberam semelhanças no grau de conhecimento, e nos livros didáticos observaram certa falta de rigor na terminologia empregada em relação aos conceitos em questão.

No Brasil, alguns trabalhos convergem nessa problemática, como a pesquisa realizada por Mól e colaboradores. Ao analisarem livros didáticos de química do Ensino Médio, foi possível observar que em relação à constante de Avogadro, alguns livros a apresentam como sendo um número determinado experimentalmente a partir de um padrão adotado, outras obras tratam da constante de forma errônea e alguns remetem à homenagem feita a Lorenzo Romano Amedeo Carlo Avogadro (1776-1856), sendo assim: "a maioria dos livros falha em fornecer aos alunos uma ideia real de como é feita tal determinação, ficando muitas vezes a ideia de que é um número mágico que surge não se sabe de onde" (MÓL et al, 1996, p. 32).

$\mathrm{Na}$ dissertação de mestrado de Rogado (2000), o autor constatou que o conceito de quantidade de matéria e a unidade, mol, apresentava sérias dificuldades de aprendizagem por parte do aluno, principalmente na distinção entre quantidade de matéria e massa. Em relação aos professores que lecionam tal conteúdo, o autor ainda afirma que:

Há uma tendência de pensamento dos professores de química sobre os conceitos de quantidade de matéria e mol desconexo do significado que lhes é atribuído pela comunidade científica: a maioria dos professores desconhece a grandeza quantidade de matéria, utilizando o 'número de mols' em seu lugar, atribuindo-lhe a ideia de uma 'massa química' ou um 'número de Avogadro' de entidades elementares (ROGADO, 2000, p. 118).

Em relação ao conteúdo nos livros didáticos (LD) brasileiros, Rogado (2000) analisou 38 LD e manuais de professores - 32 livros para o Ensino Médio e seis para o Ensino Superior, observando que nenhuma das obras relacionou o conceito de quantidade de matéria e a unidade mol a um processo de construção histórica, sendo que apenas um terço apresentava a grandeza quantidade de matéria de forma explícita no texto.

Outro trabalho que corrobora os resultados encontrados por Rogado (2000), foi realizado por Lourenço e Marcondes (2003), em que os autores verificaram que os alunos das séries iniciais do Ensino Médio, em sua maioria, definem mol como unidade de massa e não de quantidade de matéria.

Em 2006, Soares desenvolveu sua dissertação de mestrado a partir de uma proposta de abordagem histórica do conceito de quantidade de matéria. A pesquisadora aplicou um questionário aos docentes atuantes na Educação Básica e foi possível observar que a maioria não compreende corretamente o tema, sendo que os livros didáticos utilizados não colaboram para um maior entendimento, tendo como consequência na sala de aula a dificuldade de aprendizagem dos alunos. A autora defende que uma abordagem alicerçada na história da ciência pode contribuir para a compreensão da grandeza quantidade de matéria.

$\mathrm{Na}$ anseio de colaborar para a compreensão do mol, Colagrande (2008) desenvolveu em sua dissertação de mestrado, um jogo didático virtual, que tinha como objetivo principal auxiliar 
na aprendizagem do mol. Depois de aplicá-lo em sala de aula, a pesquisadora pôde perceber que a estratégia utilizada colaborou com a aprendizagem da maioria dos educandos.

Também em 2008, os pesquisadores Silva; Oki; Dotto e Moradillo apresentaram um trabalho no XIV Encontro Nacional de Ensino de Química (ENEQ) em que mostraram os resultados de uma investigação que objetivava perceber o processo de ensino-aprendizagem do conceito de quantidade de matéria. Esse trabalho fora realizado com estudantes universitários de química e apresentava dois objetivos, 1) facilitar a diferenciação entre os conceitos de quantidade de matéria, mol e massa; e 2) verificar a influência da história do conceito de quantidade de matéria na sua aprendizagem. Depois de realizada a intervenção em sala de aula, foi possível perceber que houve mudanças substanciais em relação ao conhecimento prévio, sendo que cerca de metade da turma conseguiu diferenciar quantidade de matéria e massa e também quantidade de matéria e mol. Contudo, a associação entre quantidade de matéria e quantidade de entidades elementares de um sistema material, ficou a desejar, bem como a clareza da impropriedade do emprego da expressão número de mols.

No ano de 2013, foi apresentado um trabalho no 33 o Encontro de Debates sobre o Ensino de Química (EDEQ), em que os autores mostraram os resultados de uma pesquisa realizada no âmbito do Programa Institucional de Bolsas de Iniciação à Docência (PIBID), em que os bolsistas desenvolveram uma proposta didática experimental, com o objetivo principal de diferenciar a quantidade de matéria de massa. Os pesquisadores concluíram que a abordagem experimental teve ampla receptividade dos alunos, e estes apresentaram uma melhora na compreensão de tais conceitos (ANTLER et al, 2013).

No mesmo ano Silva, Sousa e Oliveira (2013) apresentaram um trabalho no 11 ㅇ Simpósio Brasileiro de Educação Química (SIMPEQUI) em que mostraram os resultados encontrados em uma pesquisa, na qual os alunos responderam a um questionário, e nele foi possível depreender que a grandeza quantidade de matéria é apenas memorizada pelos educandos, apresentando dificuldade de compreensão de tal conceito.

Entendemos que inserir a história da ciência no ensino pode ser de grande valia para a compreensão pelo estudante de conteúdos da química. Conforme Mathews (1995) a História, bem como a Filosofia e a Sociologia da Ciência podem contribuir para a melhora na aprendizagem, pois:

\footnotetext{
Podem humanizar as ciências e aproximá-las dos interesses pessoais, éticos, culturais e políticos da comunidade; podem tornar as aulas de ciências mais desafiadoras e reflexivas, permitindo, deste modo, o desenvolvimento do pensamento crítico; podem contribuir para um entendimento mais integral de matéria científica, isto é, podem contribuir para a superação do mar de falta de significação que se diz ter inundado as salas de aula de ciências, onde fórmulas e equações são recitadas sem que muitos cheguem a saber o que significam; podem melhorar a formação do professor auxiliando o desenvolvimento de uma epistemologia da ciência mais rica e mais autêntica, ou seja, de uma maior compreensão da estrutura das ciências bem como do espaço que ocupam no sistema intelectual das coisas (p. 165).
}

Nesse sentido, acreditamos que o livro didático presente nas aulas de química das escolas públicas brasileiras, careciam de uma análise crítica da história da ciência empregada no estudo da quantidade de matéria, mol e da constante de Avogadro, uma vez que o livro didático é a principal fonte de consulta e estudo dos alunos.

\subsection{A importância do Livro Didático (LD) no processo de ensino-aprendizagem}


Segundo Gérard e Roegiers (1998), o livro didático é "um instrumento impresso, intencionalmente estruturado para se inscrever num processo de aprendizagem, com o fim de lhe melhorar a eficácia" (p. 19). Mas o que vemos na atualidade, é a utilização unânime desse instrumento em sala de aula.

Mesmo com todos os avanços tecnológicos o LD continua sendo a maior ferramenta do fazer docente na Educação Básica, o LD tem a função de guiar as atividades do professor, "no trabalho cotidiano, os professores descobrem nos livros não somente os conteúdos a serem ensinados, mas também uma proposta pedagógica que passa a influenciar de modo decisivo a ação docente" (SELLES e FERREIRA, 2004, p. 104). Já para alguns alunos, é uma fonte quase exclusiva de consulta e de estudo fora do ambiente da escola, sendo também, permeado por relações de poder, modificado com o passar do tempo, com o contexto cultural, histórico, político e econômico da sociedade (ECHEVERRÍA, MELLO e GAUCHE, 2010; MAIA et al., 2011). Sendo assim, o LD tem sido um protagonista no processo de ensino-aprendizagem. Sobre a posição ocupada na escola pelo LD, Freitag, Mota e Costa (1997) apontam:

\begin{abstract}
O livro didático não funciona em sala de aula como um instrumento auxiliar para conduzir o processo de ensino e transmissão de conhecimento, mas como o modelopadrão, a autoridade absoluta, o critério último de verdade. Neste sentido, os livros parecem estar modelando os professores. O conteúdo ideológico do livro é absorvido pelo professor e repassado ao aluno de forma acrítica e não distanciada (p.111).
\end{abstract}

Em relação à história da ciência presente no LD, os trabalhos desenvolvidos apontam para a apresentação de cientistas individualmente, negligenciando a ciência como um empreendedorismo coletivo; relegando a abordagem dos contextos e dos processos de construção da ciência (MARTINS e BRITO, 2006; PITANGA et al, 2014).

Outro obstáculo encontrado, é a abordagem dos sujeitos partícipes da construção da ciência como dotados de capacidades diferenciadas, os "gênios" (VIDAL, 2012). Nesse sentido Allchin (2003) complementa:

Um estudante com vivo interesse em ciência (mas talvez com habilidade não demonstrada) pode inferir que ela ou ele não pode fazer uma contribuição significativa a ciência - então, por que tentar? Tenho de fato encontrado estudantes que se queixam de que 'ciência é somente para gênios' (p. 343).

\title{
1.2 A distribuição do Livro Didático nas Escolas Públicas brasileiras
}

A organização em torno da distribuição dos livros didáticos, dicionários, obras literárias, que deveriam ser usados nas escolas da Educação Básica brasileira, começou a se concretizar no ano de 1929, quando foi criado um órgão - o Instituto Nacional do Livro (INL) - específico para colaborar com a legitimação do LD, auxiliando também, no aumento de sua produção.

No ano de 1938, a partir de um Decreto-Lei no 1.006, de 30/12/38 fora criada uma comissão, denominada Comissão Nacional do Livro Didático (CNLD), que tinha a incumbência de avaliar os livros que iriam ser oferecidos à comunidade estudantil. No parágrafo $3^{\circ}$, art. 10 , fica assim determinado as atribuições da Comissão:

a) Examinar os livros didáticos que Ihe forem apresentados, e proferir julgamento favorável ou contrário à autorização de seu uso; b) Estimular a produção e orientar a importação de livros didáticos; c) Indicar os livros didáticos estrangeiros de notável 
valor, que mereçam ser traduzidos e editados pelos poderes públicos, bem como sugerir-Ihes a abertura de concurso para a produção de determinadas espécies de livros didáticos de sensível necessidade e ainda não existentes no país; d) Promover, periodicamente, a organização de exposições nacionais dos livros didáticos cujo uso tenha sido autorizado na forma desta lei.

Em 1971 o INL passou a desenvolver o Programa do Livro Didático para o Ensino Fundamental (PLIDEF), e na busca de constantes aprimoramentos, no ano de 1985, a partir do Decreto 9154/85 o PLIDEF foi substituído pelo Programa Nacional do Livro Didático (PNLD), tendo como principais preceitos:

Indicação do livro didático pelos professores; Reutilização do livro, implicando a abolição do livro descartável e o aperfeiçoamento das especificações técnicas para sua produção, visando maior durabilidade e possibilitando a implantação de bancos de livros didáticos; Extensão da oferta aos alunos de 1a e 2a série das escolas públicas e comunitárias; Fim da participação financeira dos estados, passando o controle do processo decisório para a FAE e garantindo o critério de escolha do livro pelos professores. ${ }^{1}$

A Resolução/CD/FNDE no 603, de 21 de Fevereiro de 2001, passou a ser o mecanismo que organiza e regula o Plano Nacional do Livro Didático. O Ministério da educação e Cultura (MEC) criou várias comissões para a avaliação dos livros didáticos (BIEHL e BAYER, 2009). Em edital disponível no site do Fundo Nacional de Desenvolvimento da Educação (FNDE), é especificado os critérios para a inscrição de obras pelas editoras, sendo os títulos analisados pelo MEC, que ao final da avaliação cria o Guia do Livro Didático para apreciação dos docentes da Educação Básica. Assim, cada escola escolhe o livro que deseja adotar em sua instituição².

A partir do exposto acima, percebemos que o livro didático tem um papel de extrema importância no contexto escolar, e por outro lado, a história da ciência vêm sendo negligenciada ou mal usada na maioria das obras há várias décadas. Assim, buscamos discutir como a história da ciência é contemplada no tema objeto de nosso interesse.

\section{METODOLOGIA}

No presente artigo, iremos analisar os quatro livros didáticos de química (LDQ) indicados pelo PNLD 2015, observando nessas obras como as temáticas quantidade de matéria, mol e constante de Avogadro foram abordadas.

Embora saibamos que quatro livros represente um número pequeno frente à quantidade de livros editados no país, consideramos que essas obras têm uma importância significativa na educação química brasileira, uma vez que grande parcela dos jovens estudam em escolas públicas.

Inicialmente, fizemos uma leitura dos três volumes de cada obra, na busca de encontrarmos o assunto, objeto de nosso interesse. Depois de localizado, realizamos uma leitura do capítulo em que o tema era tratado. Todas as obras analisadas eram suplementadas pelo manual do professor, que também foi levado em consideração em nossa investigação. Na Tabela 1 segue os dados dos volumes trabalhados:

\footnotetext{
${ }^{1}$ Disponível em: http://www.fnde.gov.br/programas/livro-didatico/livro-didatico-historico. Acessado em: 09 jan 2016.

${ }^{2}$ Disponível em: http://www.fnde.gov.br/programas/livro-didatico/livro-didatico-apresentacao. Acessado em: 27 jan 2016.
} 


\begin{tabular}{|c|c|c|c|c|}
\hline $\begin{array}{l}\text { Código de } \\
\text { identificação } \\
\text { dos livros }\end{array}$ & Título & Autor(es) & Edição & Volume \\
\hline LDQ1 & Química & Martha Reis & $\begin{array}{l}\text { 1a ed. São Paulo: } \\
\text { Editora Ática, } 2013\end{array}$ & 1 \\
\hline LDQ2 & Química & $\begin{array}{c}\text { Eduardo Mortimer e } \\
\text { Andréa Machado }\end{array}$ & $\begin{array}{l}\text { 2a ed. São Paulo: } \\
\text { Scipione, } 2013\end{array}$ & 1 \\
\hline LDQ3 & Química cidadã & $\begin{array}{l}\text { Wildson Santos e Gerson } \\
\text { Mól (Coords.) }\end{array}$ & $\begin{array}{l}\text { 2ª ed. São Paulo: } \\
\text { AJS, } 2013\end{array}$ & 2 \\
\hline LDQ4 & $\begin{array}{c}\text { Ser Protagonista } \\
\text { - Química }\end{array}$ & Murilo Antunes (Ed. Resp.) & $\begin{array}{l}\text { 2a ed. São Paulo: } \\
\text { Edições SM, } 2013\end{array}$ & 1 \\
\hline
\end{tabular}

Tabela 1: Livros analisados.

\title{
2.1 Análise da história da ciência empregada nos LDQ recomendados em 2015
}

Na tentativa de obtermos uma apreciação histórica dos LDQ, as categorias utilizadas para a análise dos dados referentes à temática quantidade de matéria, mol e constante de Avogadro, foram inspiradas no trabalho de Laurinda Leite (2002) e adaptada por Vidal (2009).

\begin{abstract}
Essa pesquisadora [Laurinda Leite], após realizar levantamento bibliográfico, afirmou não haver encontrado nenhum instrumento adequado para a análise do conteúdo histórico presente nos livros didáticos de ciências. A partir dessa constatação, Leite desenvolveu um instrumento para preencher essa lacuna, de modo a auxiliar professores na análise crítica dos conteúdos de história da ciência encontrados em materiais didáticos. Leite reconheceu que o aprendizado sobre a natureza da ciência, e o conhecimento de alguns fatos históricos do desenvolvimento da ciência, são importantes para os diversos níveis de ensino. Todavia, nem sempre os professores possuem formação em história da ciência e, consequentemente, utilizam os materiais históricos provenientes dos livros didáticos (VIDAL, 2009, p. 43-44).
\end{abstract}

Assim, trabalhamos com as seguintes categorias: C1: Vida dos personagens; C2: Características dos personagens; C3: Abordagem das ideias/descobertas; C4: Evolução da ciência; C5: Quem faz a ciência; C6: Materiais utilizados para apresentar a informação histórica; C7: Contextos aos quais a informação histórica está relacionada (VIDAL, 2009).

Para obtermos uma análise cognitiva, nos inspiramos no trabalho desenvolvido por Rogado (2000) em sua dissertação de mestrado ${ }^{3}$ na qual o autor analisou mais de três dezenas de LDQ, em que buscava compreender como o conceito de Quantidade de Matéria era tratado.

Nesse sentido, empregamos as categorias:

C8: Explica-se o problema geral que o conceito de mol busca resolver?

C9: A grandeza quantidade de matéria é introduzida de forma explícita no texto?

\footnotetext{
${ }^{3} \mathrm{Na}$ época do desenvolvimento de seu trabalho, ainda era usado número de mols como sinônimo para quantidade de matéria.
} 
C10: No texto aparecem perguntas, questões, exercícios ou atividades sobre quantidade de matéria?

C11: Os textos apresentam questões, perguntas, exercícios ou atividades nas quais é solicitado o cálculo da quantidade de matéria?

\section{RESULTADOS E DISCUSSÃO}

$\mathrm{Na}$ categoria Vida dos personagens (C1), foi observado se os livros apresentaram as biografias dos estudiosos envolvidos na construção do conhecimento, se apresentavam certas características pessoais, além de episódios curiosos. Os resultados podem ser apreciados na Tabela 2:

\begin{tabular}{c|c|c|c|c}
\hline $\begin{array}{c}\text { Características } \\
\text { Observadas }\end{array}$ & LDQ1 & LDQ2 & LDQ3 & LDQ4 \\
\hline Dados biográficos & $\mathrm{X}$ & $\mathrm{X}$ & $\mathrm{X}$ & $\mathrm{X}$ \\
Características pessoais & - & - & $\mathrm{X}$ & - \\
Episódios / curiosidades & $\mathrm{X}$ & - & - & - \\
\hline
\end{tabular}

Tabela 2: Dados da categoria 1.

No LDQ1 em seu capítulo sete, é discutida a hipótese de Avogadro, em um quadro é mostrado uma pequena biografia do estudioso, citando somente um pouco de sua formação acadêmica. Posteriormente, comenta-se das ideias de Avogadro terem sido negligenciadas, tendo enfatizado a importância de Stanislao Cannizzaro (1826-1910), para a aceitação de suas teorias. Em seu suplemento para o professor, há uma página com o título "Conversa com o professor", em que mostra a síntese da história de Avogadro e o motivo de seus trabalhos terem sido negligenciados por tantos anos, o texto complementa a informação contida no quadro do capítulo sete.

Já no LDQ3 quando da definição da constante de Avogadro, afirmou-se que essa constante foi uma homenagem a Avogadro, nessa parte há um tópico denominado "A Ciência na História" em que mostra uma figura de Avogadro e uma pequena biografia. Quanto às características pessoais, o livro comenta simplificadamente um pouco de sua personalidade:

Isolado em seu laboratório, não viajava e correspondia-se pouco com os colegas. Seus escritos careciam de brilhantismo e simpatia, mesmo quando reportavam importantes descobertas experimentais e ideias revolucionárias, como a hipótese dos gases, publicada em 1811 (LDQ3, 2013, p. 20).

Acreditamos que a intenção dos autores seria de mostrar que um dos fatores que contribuíram para não aceitação das ideias de Avogadro num primeiro momento, poderia estar relacionada com a sua personalidade, por outro lado, essa informação que a priori possa parecer interessante, reforça a ideia que o estudante tem do cientista, como uma pessoa diferente dos padrões. Por isso, a importância de contextualizar a história que está sendo discutida, mostrando as implicações em torno de suas ideias não terem sido prontamente aceitas. Como afirma Oki 
(2009), que mesmo a proposta de Avogadro conciliando as ideias de John Dalton (1766-1844), Gay-Lussac (1778-1850), ele não foi bem sucedido, pois a aceitação da hipótese dos gases possibilitaria a diferenciação entre os conceitos de átomo e molécula, o que não aconteceu com facilidade naquele período.

Outro ponto importante está relacionado a fonte que gerou essa informação. No texto, não encontramos a referência utilizada e ao buscar dados sobre a personalidade de Avogadro em sua principal biografia, escrita pelo italiano e historiador da ciência Marco Ciardi (2006), não encontramos apontamentos que corroboram com a informação apresentada no LDQ3. Ciardi, ainda comenta que Avogadro era conhecido e respeitado por toda Europa, e que mantinha correspondências com nomes importantes da ciência da época, como por exemplo Michael Faraday (1791-1867).

Na categoria "Características dos personagens" (C2), procuramos observar como as obras caracterizavam os estudiosos, tendo como resultado:

\begin{tabular}{c|c|c|c|c}
\hline Características Observadas & LDQ1 & LDQ2 & LDQ3 & LDQ4 \\
\hline Famoso/Genial & - & - & - & - \\
Pessoa comum & $\mathrm{X}$ & - & $\mathrm{X}$ & - \\
Não há dados que caracterizem & - & $\mathrm{X}$ & - & $\mathrm{X}$ \\
\hline
\end{tabular}

Tabela 3: Dados da categoria 2.

Os livros LDQ1 e LDQ3 apresentaram os estudiosos como profissionais desenvolvendo seu ofício, não exibindo características que os diferenciassem intelectualmente do restante das pessoas. Não encontramos nos textos, uma tentativa de desmitificar o estereótipo do cientista tão comum aos alunos, de um gênio, que não apresenta uma vida próxima à realidade vivida pelos estudantes.

Zanon e Machado (2013) ao realizarem uma pesquisa com alunos iniciantes do curso de graduação em química perceberam que eles apresentam essa visão do cientista isolado, negligenciando o papel da comunidade cientifica para o desenvolvimento da ciência, os autores concluíram que:

\begin{abstract}
Os estudantes do ensino médio tendem a estereotipar o cientista como um homem maluco e solitário, o que apareceu com menos frequência nas representações dos estudantes iniciantes de ensino superior. Em ambos os casos, o cientista trabalha isolado e não fazem menção quanto à troca de informações ou da existência de uma comunidade cientifica. Quanto a essa troca de informações, no ensino superior, somente ocorreu nos desenhos relacionados com o ensino, pois segundo a legenda, seriam alunos tendo aulas no laboratório e não dois cientistas conversando sobre seus trabalhos (p. 51).
\end{abstract}

Acreditamos que os livros didáticos tem um papel singular na mudança dessa concepção dos estudantes, influenciando suas opiniões sobre quem faz ciência. Há de se fazer um esforço para incluir a história dos personagens de forma a contribuir para a mudança dessa visão de cientista.

$\mathrm{Na}$ categoria C3, "Abordagem das ideias/descobertas", observamos como as obras abordavam a ideia científica. Quando ocorria somente uma pequena alusão dos estudiosos, sem 
explicações sobre o assunto, consideramos como menção à ideia cientifica. Por outro lado, quando ocorria a sua descrição, englobando a descrição da ideia científica, da teoria, do contexto histórico, explicação da metodologia adotada, consideramos como uma descrição da ideia abordada.

\begin{tabular}{|c|c|c|c|c|}
\hline Apresentação do conteúdo & LDQ1 & LDQ2 & LDQ3 & LDQ4 \\
\hline $\begin{array}{c}\text { Menção a uma ideia } \\
\text { científica }\end{array}$ & - & $x$ & - & - \\
\hline $\begin{array}{l}\text { Descrição de uma ideia } \\
\text { científica }\end{array}$ & $x$ & - & $x$ & $x$ \\
\hline
\end{tabular}

Tabela 4: Dados da categoria 3.

Podemos perceber pela Tabela 4, que a maioria dos livros fazem uma descrição da ideia cientifica. Consideramos que o LDQ3 fez uma descrição da ideia cientifica, uma vez que procurou explicar a importância de Avogadro para a determinação do que mais tarde foi denominado por constante de Avogadro.

O cientista propôs que muitos gases são formados por moléculas as quais contêm mais de um átomo, por exemplo, os gases hidrogênio $\left(\mathrm{H}_{2}\right)$, oxigênio $\left(\mathrm{O}_{2}\right)$ e cloro $\left(\mathrm{Cl}_{2}\right)$. Sabendo que os gases hidrogênio e oxigênio são constituídos por moléculas diatômicas e que a proporção de volumes desses gases para formar a água é de dois para um, ele concluiu que a proporção entre seus átomos também seria essa, ou seja, a fórmula deveria ser $\mathrm{H}_{2} \mathrm{O}$ e não $\mathrm{HO}$, como era considerada até então. Mesmo com dificuldades para medir a massa dos gases, Avogadro chegou à razão de 15,074 entre as massas dos átomos de oxigênio e hidrogênio, sendo a última considerada igual a uma unidade. Ele não estabeleceu o valor da constante de Avogadro, mas lançou as bases teóricas que possibilitaram a determinação. Por isso, em homenagem a ele, a constante recebeu o seu nome. Amedeo Avogadro concluiu que, se volumes iguais contêm o mesmo número de moléculas, é possível determinar as massas moleculares relativas. Dessa forma, tornou possível explicar substâncias como o $\mathrm{NH}_{3}, \mathrm{NO}, \mathrm{NO}_{2}, \mathrm{HCl}, \mathrm{CO}_{2}$ e $\mathrm{SO}_{2}$, demonstrando como predizer as fórmulas e as massas molares com grande precisão (LDQ3, p. 21).

O LDQ4, descreveu simplificadamente um experimento para determinação da constante, depois dos trabalhos desenvolvidos por Jean Perrin:

Foi o trabalho desenvolvido pelo radioquímico Bertram Boltwood (1870-1927) e pelo físico E. Rutherford (1871-1937) que permitiu a determinação mais precisa da $\mathrm{N}_{\mathrm{A}}$. De maneira simplificada, o experimento consistia na contagem de partículas $\alpha$ emitidas por uma fonte radioativa e na determinação do volume do gás hélio. [...] Atualmente, o valor da $N_{A}$ utilizado é obtido por meio de difração de raios $X$. $A$ técnica consiste na determinação do volume de alguns átomos de um retículo cristalino, cuja massa de $1 \mathrm{~mol}$ de átomos e a densidade da amostra sejam conhecidas (p. 261).

Ambos fragmentos anteriores, do LDQ3 e do LDQ4 não apresentaram a referência da informação histórica. A partir dos fragmentos, realizamos uma pesquisa on-line na procura pelo 
embasamento teórico dessas citações, e não encontramos trabalhos que nos possibilitasse inferir a fonte da consulta.

O LDQ1, ao explicar a origem do mol, a autora afirma que: "A palavra mol, introduzida em 1896 pelo químico alemão Wilhelm Ostwald (1853-1932), vem do latim moles, que significa 'porção, quantidade'”' (p.127-128), não há uma discussão das mudanças conceituais ocorridas através do tempo até que o mol tivesse o significado atual. Da forma que fora abordado, aparenta que não houve nenhuma discussão ou mudança na definição do mol. Em contrapartida, ao trazer o tópico da constante de Avogadro, a autora faz uma descrição interessante do raciocínio realizado por Avogadro a partir dos experimentos com gases feitos por Gay-Lussac.

Acreditamos que uma descrição completa da ideia cientifica contribuiria para que o aluno compreendesse como se deu a construção do conhecimento em torno da temática mol, o tratamento superficial da história, com uma simples exemplificação de um personagem, sem maiores detalhes de seus trabalhos não contribui com a aprendizagem do aluno. Como afirmam Kosminsky e Giordan (2002):

As dificuldades de entendimento dos fenômenos tratados nas salas de aula de Ciências, e mesmo a ausência de motivação para estudá-los, podem ser atribuídas, em parte, ao desconhecimento das teorias sobre o funcionamento da Ciência, tanto por parte dos professores como dos estudantes (p.18).

Na categoria Evolução da ciência (C4), consideramos como menção a períodos discretos quando dois ou mais períodos ou ideias são mencionados, não é mostrado uma relação clara entre eles. Quando ocorria uma relação entre os períodos citados, aparentemente linear, consideramos como evolução direta e como evolução real, quando ocorria a discussão com movimento de idas e voltas e acontecimentos controversos.

\begin{tabular}{c|c|c|c|c}
\hline $\begin{array}{c}\text { Apresentação do } \\
\text { conteúdo }\end{array}$ & LDQ1 & LDQ2 & LDQ3 & LDQ4 \\
\hline $\begin{array}{c}\text { Menção a períodos } \\
\text { discretos }\end{array}$ & - & - & $\mathrm{X}$ & $\mathrm{X}$ \\
$\begin{array}{c}\text { Evolução linear e direta } \\
\text { Evolução real }\end{array}$ & - & $\mathrm{X}$ & - & - \\
\hline
\end{tabular}

Tabela 5: Dados da categoria 4.

O LDQ1, no capítulo que trata de átomos e moléculas, Avogadro é citado algumas vezes durante a contextualização sobre as mudanças conceituais ocorridas em torno do que se considerava molécula. A obra discute a construção do conhecimento, e as divergências que existiam entre Dalton e Gay-Lussac, mostrando as conclusões que Avogadro chegou. Nesse mesmo capítulo, é discutida a hipótese de Avogadro e, em um quadro é mostrado uma pequena biografia do estudioso, citando somente um pouco de sua formação acadêmica.

Observamos que houve uma preocupação em mostrar as rupturas, as formas distintas de pensar os fenômenos. Essa forma de abordagem pode contribuir para que o aluno compreenda a complexidade para a consolidação de uma determinada teoria.

No LDQ2, é mostrado uma relação linear da ciência, quando trata-se do mol, é comentado: 
A relação entre esse número e a respectiva quantidade é conhecida como constante de Avogadro $\left(6,02 \cdot 10^{23} / \mathrm{mol}\right)$ em homenagem ao químico italiano Amedeo Avogadro (1776-1856), que, no início do século XIX, deu contribuições importantes para o avanço da hipótese atômica formulada por Dalton. Avogadro propôs uma hipótese que sugeria a possibilidade de "contar" átomos e moléculas (p. 262).

Na sequência, "numa publicação de 1811, Avogadro assim se referia àquilo que mais tarde se tornaria conhecido como Hipótese de Avogadro ou, ainda, Lei de Avogadro" (p.262). E por fim:

A possibilidade de contar átomos e moléculas foi concretizada quase cem anos depois. Em 1913, Jean Perrin publicava um livro intitulado Les Atomes, em que se referia a trinta maneiras diferentes de determinar a constante de Avogadro (p. 262).

Quando a construção do conhecimento é tratada de forma linear, favorece a concepção do aluno de que os cientistas apenas melhoram e complementam uma ideia anterior, como Bizzo (1992) afirma, a ideia de que o passado teria a função de auxiliar a compreensão do presente, pressupondo a existência de um continuum. Complementarmente, Martins (1998) pondera que ao abordar a história da ciência deve-se evitar a adoção de uma visão ingênua da ciência, como sendo a verdade ou aquilo que foi aprovado, alguma coisa de eterno e imutável, construída por gênios que não cometem erros.

$\mathrm{Na}$ categoria C5 - Quem faz a ciência, observamos se o cientista era apresentado individualmente, sendo o único responsável pela descoberta, se trabalhava em grupo, quando dois ou mais pesquisadores trabalharam juntos e quando a descoberta se deu pela comunidade cientifica, quando trata dos estudiosos de um período, sem especificar nomes.

\begin{tabular}{c|c|c|c|c}
\hline $\begin{array}{c}\text { Apresentação do } \\
\text { conteúdo }\end{array}$ & LDQ1 & LDQ2 & LDQ3 & LDQ4 \\
\hline $\begin{array}{c}\text { Personagens individuais } \\
\text { Grupos de personagens }\end{array}$ & $\mathrm{X}$ & $\mathrm{X}$ & - & $\mathrm{X}$ \\
Comunidade científica & - & - & - & - \\
\hline
\end{tabular}

Tabela 6: Dados da categoria 5.

Todas as obras, enfatizam sobremaneira a importância de Avogadro para a determinação da constante de Avogadro, sendo que o primeiro a determiná-la - Jean Perrin - é tratado de forma secundária, não há ênfase na importância de seu trabalho, que culminou no Prêmio Nobel de Física por ele recebido em 1926.

No LDQ3, é mencionado que vários cientistas estavam em busca de mensurar o valor para a constante de Avogadro:

Como não podiam precisar o valor da constante de Avogadro, vários químicos e físicos (inclusive Albert Einstein) propuseram métodos indiretos para determiná-lo. Como? Sabendo que muitas propriedades das substâncias dependem da quantidade de entidades químicas (átomos, moléculas, íons etc.), apresentaram técnicas específicas para medir tais propriedades e metodologias de cálculos as quais fornecem a constante de Avogadro, ou seja, o número de entidades presentes em um mol (p. 20). 
Valorizar o trabalho da comunidade científica pode contribuir para a compreensão de colaboração entre pares, de pessoas que buscam o mesmo objetivo, contribuindo também, para desmitificar a visão do cientista como solitário. Mas deve-se estar atento a contextualização de aspectos sócio históricos, pois a sua ausência e, sobretudo seu mau uso, acabam por gerar visões distorcidas da natureza da ciência (Silva e Pimentel, 2008).

Na categoria C6: Materiais utilizados para apresentar a informação histórica, observamos quais materiais foram adotados, a saber:

\begin{tabular}{c|c|c|c|c}
\hline Apresentação do conteúdo & LDQ1 & LDQ2 & LDQ3 & LDQ4 \\
\hline Imagens dos personagens & - & $\mathrm{X}$ & $\mathrm{X}$ & $\mathrm{X}$ \\
Imagens dos equipamentos & - & - & - & - \\
Documentos / Textos originais & - & $\mathrm{X}$ & - & - \\
Descrição de experimentos & - & - & - & - \\
históricos & $\mathrm{X}$ & - & $\mathrm{X}$ & $\mathrm{X}$ \\
Fontes secundárias & - & - & - & - \\
Outros (selos, cédulas, etc.) & & & & \\
\hline
\end{tabular}

Tabela 7: Dados da categoria 6.

No LDQ2, quando os autores tratam da hipótese de Avogadro, é mostrando uma ilustração de Avogadro. Não há menção à biografia, porém há uma reprodução do texto original do estudioso, como o enunciado do que mais tarde ficou conhecido como hipótese de Avogadro.

Tem de ser admitido que uma relação muito simples também existe entre os volumes de substâncias gasosas e o número de moléculas simples ou compostas que as constituem. A primeira hipótese a se apresentar em relação a isso, e aparentemente a única admissível, é a suposição de que o número de moléculas integrantes em qualquer gás é sempre o mesmo para volumes iguais ou é sempre proporcional ao volume.

AVOGADRO, Amedeo, apud PARTINGTON, James Riddick. A History of Chemistry. London: MacMillan, 1964. v. 4. p. 214

Figura 1: Imagem extraída do LDQ2. Fonte: LDQ2, p. 262.

Em seguida, é ilustrado a capa do livro de Jean Perrin, onde ele mostrou os cálculos realizados para determinação da constante. 


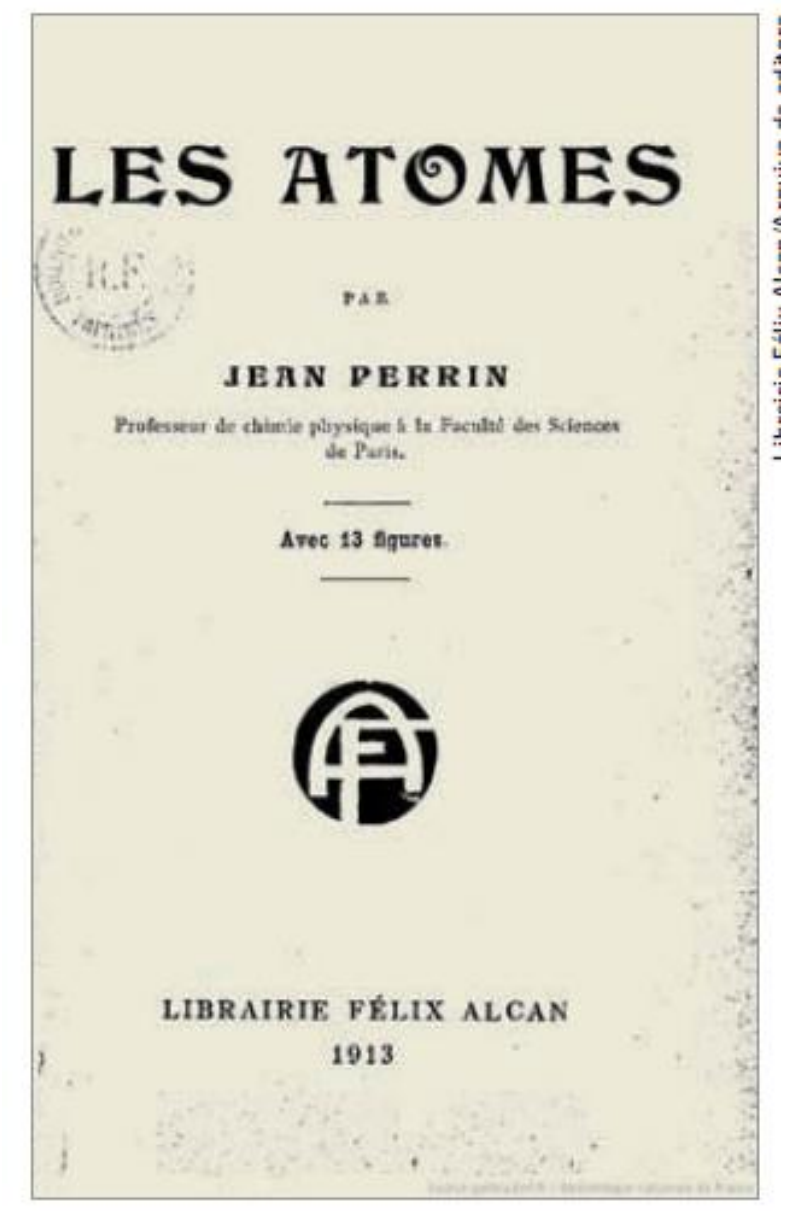

Figura 2: Imagem extraída do LDQ2. Fonte: LDQ2, p. 262.

As fontes primárias podem ser uma ferramenta para não perpetuar erros conceituais contidos em obras antecessoras, sendo uma rica forma de aproximar o aluno da história da ciência. Martins (2001) afirma a importância de se trabalhar com fontes primárias:

\footnotetext{
A história da ciência não é feita simplesmente de opiniões, repetições e boatos, ela é desenvolvida a partir do estudo de documentos. Uma biblioteca cheia de documentos antigos representa, para o historiador, aquilo que o laboratório representa para o físico atual: é o modo de testar ideias, de verificar até que ponto uma hipótese ou teoria está de acordo com os fatos (p. 115).
}

A falta de material primário nos livros gera, para os professores que almejam trabalhar suas aulas numa perspectiva histórica, terem que recorrer a materiais complementares, que infelizmente não são de fácil acesso (Martins, 2000).

Na categoria C7 - Contextos aos quais a informação histórica está relacionada ao contexto científico (conhecimento cientifico ou matemático disponível ou ausente na época); tecnológico (relaciona-se à tecnologia disponível ou ausente na época); social (condições de vida e aos valores da época); político (relaciona-se à política da época) e religioso (relaciona-se às crenças religiosas da época). 


\begin{tabular}{c|c|c|c|c}
\hline Apresentação do conteúdo & LDQ1 & LDQ2 & LDQ3 & LDQ4 \\
\hline Científico & & & & \\
Tecnológico & $\mathrm{X}$ & $\mathrm{X}$ & $\mathrm{X}$ & $\mathrm{X}$ \\
Social & - & - & - & - \\
Político & $\mathrm{X}$ & - & - & - \\
Religioso & - & - & - & - \\
\hline
\end{tabular}

Tabela 8: Dados da categoria 7.

Nessa categoria, podemos ver uma predominância da abordagem do contexto científico em detrimento das demais abordagens. Dessa forma, o educando não tem a possibilidade de fazer uma leitura do mundo que cercava os estudiosos que trabalhavam com o tema, suas principais angústias, os fatores religiosos e políticos que contribuíram ou prejudicaram suas pesquisas.

Ao realizarmos a análise cognitiva do conceito de Quantidade de matéria, mol e constante de Avogadro nos LDQ recomendados em 2015 buscamos dialogar com resultados de James Rogado. Criamos um gráfico com as categorias C8 a C11 (C8: Explica-se o problema geral que o conceito de mol busca resolver? C9: A grandeza quantidade de matéria é introduzida de forma explícita no texto? C10: No texto aparecem perguntas, questões, exercícios ou atividades sobre quantidade de matéria? C11: Os textos apresentam questões, perguntas, exercícios ou atividades nas quais é solicitado o cálculo da quantidade de matéria? Na coluna denominada "2000", colocamos os resultados encontrados por Rogado e na coluna "2015", inserimos nossos resultados. Assim, no Gráfico 1, podemos perceber as diferenças encontradas no intervalo de 15 anos.

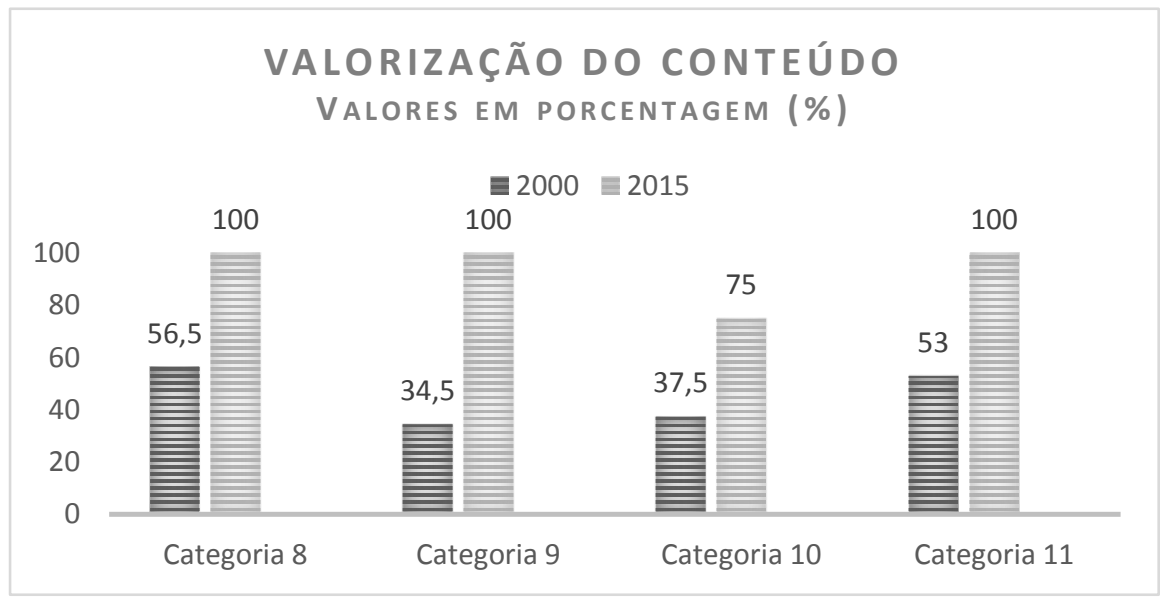

Gráfico 1: Um diálogo com os resultados de Rogado (2000).

Podemos perceber um avanço significativo na abordagem da grandeza Quantidade de Matéria nos livros didáticos atuais. É possível notar que os LDQ atuais buscam explicar detalhadamente a importância da grandeza e da unidade mol para o estudo da química.

Podemos perceber pelo Gráfico 1, que houve uma melhora expressiva na abordagem da temática nos livros editados nos últimos anos. Acreditamos que com o aumento da publicação de trabalhos que iam na direção de mostrar que o educando e o professor apresentam dificuldades 
conceituais ao estudar a grandeza quantidade de matéria, os autores começaram a refletir sobre a importância da abordagem que deveria ser empregada em suas obras.

Há ainda que procurar melhorar o enfoque que se dá às questões referentes à quantidade de matéria que não estão relacionadas diretamente à aplicação de fórmulas, na tentativa de contribuir para a consolidação do conceito e não somente de sua aplicação.

\section{CONCLUSÃO}

Por toda a trajetória que apresentamos, percebemos que é constante a busca dos órgãos competentes governamentais, pela melhoria da qualidade dos livros didáticos distribuídos nas escolas públicas brasileiras. A criação de comissões para analisar criticamente os livros publicadas nos mostra uma preocupação por levar até o educando um material que apresente melhor qualidade.

A partir dos resultados, percebemos que as obras ainda precisam passar por uma adaptação na abordagem da história da ciência, deve-se não apenas contemplar a imagem dos cientistas e do perfil de homem solitário, mas sim, buscar fazer uma contextualização sócio histórica, mostrando todas as implicações para que um conceito ou teoria possa ser aceito por uma comunidade científica.

As obras ainda carecem de aproximar o estudante a uma ciência não linear, de caráter menos positivista, deve-se mostrar ao aluno que o percurso para a construção do conhecimento é permeado por idas e vindas e que durante o processo há erros. Além de enfatizar a importância da comunidade científica, mostrando as correspondências entre os pares, suas colaborações em detrimento do cientista e descobridor isolado.

A tentativa de trazer materiais primários para o texto do livro didático deve ser incentivada cada vez mais, é a partir desse material, que o aluno e o professor podem se aproximar do conteúdo que estão trabalhando, além de terem acesso a um texto fidedigno, que não passou por processos de interpretações de outrem.

Em relação à abordagem cognitivista do tema, houve uma acentuada melhora nos últimos anos, alavancada pelo número crescente de trabalhos que mostravam a importância de melhor trabalhar a temática.

Acreditamos que os LDQ adotados pelo PLND 2015, não contempla de forma satisfatória a história da ciência quando apresentam a quantidade de matéria. Esse assunto é exposto a partir de uma abordagem historiográfica parcial, considerado na maioria das vezes em recortes do texto principal e figuras dos pesquisadores, não colaborando para que o educando compreenda a natureza do conhecimento científico.

Nesse sentido, os historiadores da ciência, poderiam contribuir com a elaboração das obras, na busca por trazer informações historiográficas que contemple os moldes da historiografia da ciência atual.

Acreditamos que uma abordagem alicerçada na HC possa contribuir para a aprendizagem de uma temática que ainda é pouco compreendida pelos estudantes, podendo também, cooperar com a prática docente, uma vez que o professor também utiliza-se dos livros didáticos para preparação de suas aulas. 


\section{REFERÊNCIAS}

ABRANTES, A. F. P., VIEIRA, C. S. G., SILVA, M. F. P. Estudo sobre "Quantidade de substância" e Mole. Boletim Sociedade Portuguesa de Química, v. 90, p. 65-68, 2003.

ALLCHIN, D. Scientific myth-conceptions. Science Education, v. 87, p. 329-351, 2003.

ANTLER, M., MARION, A. L. M., COSTA, D. R. M., NUNES, J. G., ZUCOLOTTO, A. M., GUERREIRO, L. M. S., PIZZATO, M. C. "Conhecendo o Mol": uma proposta didática para o Ensino de Química. In: $33 \quad$ o $\quad$ EDEQ, 2013.2 Disponível em: https://www.revistas.unijui.edu.br/index.php/edeq/article/view/2670/2248. Acessado em: 12 jun 2015.

ANTUNES, M. T. Ser Protagonista - Química. São Paulo: Edições SM, v. 1, 2013.

BIEHL, J. V., BAYER, A. A escolha do livro didático de matemática. Em: 5o Encontro Gaúcho de Educação Matemática, ljuí, 2009. Disponível em: http://www.projetos.unijui.edu.br/matematica/cd_egem/fscommand/CC/CC_43.pdf. Acessado em 12 jun 2015.

BIZZO, N. M. V. História da ciência e ensino: onde terminam os paralelos possíveis? Em Aberto, v. 11, n. 55, p. 29-35, 1992.

BRASIL. Guia de livros didáticos PNLD 2015: química ensino médio. Brasília: Secretaria de Educação Básica, 2014.

BRASIL. Decreto-Lei n. 1.006, de 30 de dezembro de 1938. Estabelece as condições de produção, importação e utilização do livro didático. Diário Oficial da União, Brasília, DF, 1938. Disponível em: <http://www2.camara.leg.br/legin/fed/declei/1930-1939/decreto-lei-1006-30-dezembro1938-350741-publicacaooriginal-1-pe.html>. Acessado em: 10 jun 2015.

CIARDI, M. Amedeo Avogadro - Una politica per la scienza. Roma: Carocci, 2006.

COLAGRANDE, E. A. Desenvolvimento de um jogo didático virtual para o aprendizado do conceito de mol. São Paulo, 2008. Dissertação de mestrado - Universidade de São Paulo, 2008.

DIERKS, W. Teaching the mole. European Journal of Science Education, v. 3, n.2, p. 145-148, 1981.

ECHEVERRÍA, A. R., MELLO, I. C., GAUCHE, R. Livro didático: análise e utilização no ensino de química. Em W. L. P. Santos e O. A. Maldaner (Orgs.), Ensino de Química em Foco, ljuí: Unijuí, p. 263-286, 2010.

FREITAG, B., MOTTA, V. R., COSTA, W. F. O livro didático em questão. 3a Ed. São Paulo: Cortez, 1997.

FURIÓ, C., AZCONA, R., GUISASOLA, J. Revisión de investigaciones sobre la enseñanza-aprendizaje de los conceptos cantidad de sustância y mol. Enseñanza de las Ciencias, v. 20, n.2, p. 229242, 2002.

GÉRARD, F. M., ROEGIERS, X. Concevoir et évaluer des manuels scolaires. Bruxelas: De BoeckWesmâel, 1998.

KOSMINSKY, L., GIORDAN, M. Visões de Ciências e sobre Cientista Entre Estudantes do Ensino Médio. Química Nova na Escola, v. 15, p. 11-18, 2002.

LEITE, L. History of science in science education: development and validation of a checklist for analysing the historical content of science textbooks. Science \& Education, v. 11, n. 4, p. 333359, 2002.

LOURENÇO, I. M. B., MARCONDES, M. E. R. Um plano de ensino para mol. Química Nova na Escola, v. 18, p. 22-25, 2003.

MAIA, J. O., SÁ, L. P., MASSENA, E. P., WARTHA, E. J. O livro didático de química nas concepções de professores do ensino médio da região sul da Bahia. Química Nova na Escola, v. 33, n.2, p. 115-124, 2011. 
MARTINS, L. A., BRITO, A. P. O. P. M. A História da Ciência e o ensino de genética e evolução no nível médio: um estudo de caso. Em: C. C. Silva (Org.), Estudos de História e Filosofia das Ciências: subsídios para aplicação no ensino, São Paulo: Editora Livraria da Física, p. 245-264, 2006.

MARTINS, R. A. Que Tipo de História da Ciência Esperamos Ter nas Próximas Décadas? Episteme, v. 10, p. 39-56, 2000.

MARTINS, R. A. Como não escrever sobre história da física: um manifesto historiográfico. Revista Brasileira de Ensino de Física, v. 33, n. 1, p. 113-129, 2001.

MARTINS, L. A.P. A História da Ciência e o Ensino de Biologia. Ciência e Ensino, v. 7, p. 18-21, 1998.

MATTHEWS, M. R. História, Filosofia e Ensino de Ciências: A tendência atual de reaproximação. Caderno Catarinense de Ensino de Física, v. 12, n.3, p. 164-214, 1995.

MÓL, G. S., FERREIRA, G. A. L., SILVA, R. R. da, LARANJA, H. F. Constante de Avogadro. Química Nova na Escola, v. 3, p. 32-33, 1996.

MORTIMER, E. F., MACHADO, A. H. Química. São Paulo: Scipione, v. 1, 2013.

OKI, M. C. M. Controvérsias sobre o atomismo no século XIX. Quim. Nova, v. 32, n.4, p. 1072-1082, 2009.

PITANGA, A. F., SANTOS, H. B., GUEDES, J. T., FERREIRA, W. M., SANTOS, L. D. História da Ciência nos Livros Didáticos de Química: Eletroquímica como Objeto de Investigação. Química Nova na Escola, v. 1, p. 11-17, 2014.

REIS, M. Química. São Paulo: Editora Ática, v. 1, 2013.

ROGADO, J. Quantidade de matéria e mol; concepções de ensino e aprendizagem. Piracicaba, 2000. Dissertação de Mestrado - Universidade Metodista de Piracicaba, 2000.

ROJO, R., BATISTA, A.A.G. Livro didático de língua portuguesa, letramento e cultura escrita. São Paulo: Mercado das Letras, 2003.

SANTOS, W. L. P. dos, MÓL, G. S. Química Cidadã. São Paulo: AJS, v. 2, 2013.

SELLES, E. S.; FERREIRA, M. S. Influências Histórico-culturais nas representações sobre as estações do ano em livros didáticos de ciências. Ciência \& Educação, v. 10, n. 1, p. 101-110, 2004.

SILVA, J. L. P. B., OKI, M. V. M., DOTTO, R. R., MORADILLO, E. F. Ensino-Aprendizagem do conceito quantidade de matéria. In: XIV Encontro Nacional de Ensino de Química. Paraná, 2008. Disponível em: <http://www.quimica.ufpr.br/eduquim/eneq2008/resumos/R0298-2.pdf>. Acesso em 09 jan 2016.

SILVA, C. C.; PIMENTEL A. C. Uma análise da história da eletricidade presente em livros didáticos: o caso de Benjamin Franklin. Caderno Brasileiro de Ensino de Física, v. 25, n.2, p. 141-159, 2008.

SILVA, C.F., SOUSA, P.A.A., OLIVEIRA, L.B. A quantidade de matéria: Uma questão além do conceito. In: 11을 Simpósio Brasileiro de Educação Química. Teresina, 2013. Disponível em: <http://www.abq.org.br/simpequi/2013/trabalhos/2228-16094.htmls. Acesso em 09 jan 2016.

SOARES, M. A. C. P. A grandeza "quantidade de matéria" e sua unidade "mol": Uma Proposta de Abordagem Histórica no Processo de Ensino-Aprendizagem. Maringá, 2006. Dissertação de Mestrado - Universidade Estadual de Maringá, 2006.

SOARES, M. B. Novas práticas de leitura e escrita: letramento na Cibercultura. Educação e Sociedade, v. 23, n. 81, p. 141-160, 2002.

VIDAL, P. H. O. A História da Ciência nos Livros Didáticos de Química do PNLEM 2007. São Paulo, 2009. Dissertação de Mestrado - Universidade de São Paulo, 2009.

VIDAL, P. H. O., PORTO, P. A. A História da Ciência nos Livros Didáticos de Química do PNLEM 2007. Ciência \& Educação, v. 18, n. 2, p. 291-308, 2012.

ZANON, D. A. V., MACHADO, A. T. A visão do cotidiano de um cientista retratada por estudantes iniciantes de licenciatura em Química. Revista Ciência e Cognição, v. 18, p. 46-56, 2013. 